DOI: https://doi.org/10.24127/ajpm.v9i2.2599

\title{
PEMBELAJARAN MATEMATIKA MENGGUNAKAN KERANGKA KERJA RECCE UNTUK MENDUKUNG KOMPETENSI KOGNITIF
}

\author{
Alifia Gunita Ningsih ${ }^{1}$, Arif Hidayatul Khusna ${ }^{2 *}$, Anis Farida Jamil ${ }^{3}$ \\ 1,2,3 Pendidikan Matematika, Universitas Muhammadiyah Malang, Malang, Indonesia \\ *Corresponding author. Universitas Muhammadiyah Malang, Malang, Indonesia \\ E-mail: $\quad \underline{\text { khusna@umm.ac.id }}^{2 *}$
}

Received 09 January 2020; Received in revised form 11 June 2020; Accepted 21 June 2020

\begin{abstract}
Abstrak
Tujuan dari penelitian ini adalah mendeskripsikan penerapan pembelajaran matematika dengan menggunakan kerangka kerja RECCE (realistic, educational, cognitive, contextual, and evaluation) untuk mendukung kompetensi kognitif mahasiswa. Penelitian ini menggunakan pendekatan kualitatif deskriptif untuk menggambarkan proses pembelajaran yang terjadi. Produk penelitian ini adalah Rencana Pelaksanaan Pembelajaran (RPP). Instrumen penelitian menggunakan lembar validasi untuk menilai kelayakan RPP sebelum diterapkan dan lembar keterlaksanaan pembelajaran yang digunakan untuk mendeskripsikan aktivitas mahasiswa selama pembelajaran. Teknik pengumpulan data melalui observasi sedangkan teknik analisis data terdiri dari tiga tahap yaitu reduksi, penyajian data, dan penarikan kesimpulan. Hasil dari penelitian ini adalah kerangka kerja RECCE berhasil mendukung kompetensi kognitif mahasiswa. Mahasiswa aktif dalam mengungkapkan pendapat, berdiskusi, dapat memberikan contoh nyata pada translasi, dapat menjelaskan definisi translasi menggunakan bahasa sendiri, dapat membuktikan teorema pada translasi, dapat menyelesaikan masalah translasi yang disajikan, dan dapat mengerjakan lembar kerja mahasiswa (LKM) sesuai dengan pemahaman yang didapat. Berdasarkan keaktifan mahasiswa selama pembelajaran berlangsung maka penggunaan kerangka kerja RECCE pada translasi sudah tepat digunakan dalam mendukung kompetensi kognitif mahasiswa.
\end{abstract}

Kata kunci: Kerangka kerja RECCE; kompetensi kognitif.

\begin{abstract}
The purpose of this study is to describe the application of mathematics learning by using the RECCE framework to support student cognitive competencies. This study uses a descriptive qualitative approach to describe the learning process that occurs. The product of this research is the RPP. The research instrument used a validation sheet to assess the feasibility of the lesson plan before it was implemented and the sheet of learning accomplishment was used to describe student activities during learning. The technique of collecting data through observation while the data analysis technique consists of three stages, namely reduction, presentation of data, and drawing conclusions. The results of this study are that the RECCE framework successfully supports student cognitive competence. Students are active in expressing opinions, discussing, can give real examples on translation, can explain the definition of translation using their own language, can prove theorems on translation, can solve the translation problems presented, and can do student worksheet in accordance with the understanding obtained. Based on the activeness of students during the learning process, the use of the RECCE framework on translation is appropriate to be used in supporting students' cognitive competence.
\end{abstract}

Keywords: RECCE framework; cognitive competence.

\section{PENDAHULUAN}

Disadari atau tidak bahwa saat ini matematika memiliki peran penting dalam kehidupan. Matematika sangat berpengaruh dalam berbagai bidang terutama pada bidang pendidikan. Peran penting pendidikan pada pembelajaran matematika diantaranya untuk melahirkan manusia berkualitas, cerdas, kreatif, terampil, dan inovatif serta mampu berpikir logis (Annur, Sujadi, \& 
Subanti, 2016; Ariawan \& Nufus, 2017).

Pentingnya matematika dalam berbagai bidang terutama dalam bidang pendidikan, perlu dikembangkan suatu pembelajaran yang dapat mendorong mahasiswa untuk berpikir logis dalam memecahkan masalah yang berkaitan dengan kehidupan sehari-hari (Ardiyani, Gunarhadi, \& Riyadi, 2018; Ariawan \& Nufus, 2017; Nurjaman, Purwasih, \& Sari, 2018). Pembelajaran matematika yang berkaitan dengan kehidupan sehari-hari perlu diterapkan agar mahasiswa benar-benar memahami materi yang didapat sehingga kompetensi kognitifnya dapat berkembang.

Kompetensi kognitif diartikan sebagai proses pengembangan mental dan berpikir seseorang, dimana pada proses ini harus terdapat keyakinan (beliefs), keinginan (desires), dan niat (intentions) dengan melibatkan pengetahuan, keahlian, dan pembelajaran (Ekawati, Kohar, Imah, Amin, \& Fiangga, 2019). Ketiga unsur tersebut yaitu pengetahuan, keahlian, dan pembelajaran harus tertuang dalam suatu penugasan atau ujian.

Berdasarkan fakta di lapangan mahasiswa masih kurang memahami materi matematika yang telah diajarkan jika belum mengerjakan soal atau diberikan tugas. Fakta tersebut diperkuat dengan pernyataan bahwa pemberian tugas atau pelaksanaan ujian merupakan kegiatan dalam mendukung kompetensi kognitif mahasiswa (Akbay, Terzi, Kaplan, \& Karaaslan, 2018). Oleh karena itu untuk memantapkan materi yang telah diajarkan, perlu diberikan tugas sebagai latihan sehingga kompetensi kognitif siswa maupun mahasiswa dapat terasah.

Selain itu untuk mendukung kemampuan kognitif mahasiswa diperlukan suatu kerangka kerja yang sejalan dengan pembelajaran matematika yang berkaitan dengan kehidupan nyata.

Penelitian ini sejalan dengan penelitian Ramirez, Shaw, \& Maloney (2018) yang mengatakan bahwa penggunaan kerangka kerja yang tepat dapat mendukung pembelajaran untuk mencapai hasil maksimal, apabila pembelajaran matematika erat kaitannya dengan kehidupan nyata, maka harus menerapkan kerangka kerja yang dapat mengintegrasi suatu permasalahan ke dalam kehidupan sehari-hari sehingga penerapannya berjalan seimbang. Penelitian ini juga sejalan dengan penelitian Agrawal \& Morin (2016) yang mengatakan bahwa pembelajaran yang didukung dengan kerangka kerja yang sesuai, dapat membantu menghubungkan pengetahuan konseptual terhadap dunia nyata sehingga keberhasilan pembelajaran dapat tercapai. Keberhasilan pembelajaran sangat ditentukan melalui kualitas kerangka kerja atau rancangan pembelajaran yang dibuat dan digunakan (Indriani, 2017).

Kerangka kerja RECCE

(Realistic, Educational, Contextual, Cognitive, and Evaluation) diyakini dapat mendukung kompetensi kognitif mahasiswa. Kerangka kerja RECCE memiliki beberapa unsur, diantaranya realistic pada kerangka kerja RECCE berhubungan dengan kehidupan nyata. Unsur educational bertujuan untuk mendorong mahasiswa agar aktif saat pembelajaran matematika berlangsung dengan cara memberikan contoh, beraktivitas, maupun mengerjakan tugas. Unsur cognitive mengacu pada pengembangan keterampilan berpikir dengan cara komunikasi, mencari solusi, dan memecahkan masalah. Unsur contextual yaitu menghubungkan 
konsep dan ide matematika serta membantu mahasiswa untuk terlibat dalam permasalahan nyata. Unsur yang terakhir pada kerangka kerja RECCE adalah evaluation, unsur evaluation kegiatannya lebuh cenderung pada aktivitas dosen yaitu memberikan umpan balik serta memberikan penguatan terhadap pembelajaran yang dilaksanakan (Chong, Shahrill, \& Li, 2019)

Di Indonesia, kerangka kerja RECCE masih belum diterapkan pada pembelajaran matematika. Padahal kerangka kerja RECCE dapat diterapkan untuk mengembangkan dan mengintegrasikan pemecahan masalah yang berhubungan dengan kehidupan sehari-hari dan dituangkan dalam pembelajaran di dalam kelas sehingga dapat memudahkan mahasiswa dalam memahami materi. Pernyataan tersebut didukung oleh pernyataan Chong, Shahrill, \& Li, (2019) pada penelitiannya yang mengatakan bahwa penerapan kerangka kerja $R E C C E$ dapat digunakan untuk memasukkan permasalahan di dunia nyata ke dalam pembelajaran untuk mendukung pengembangan kognitif mahasiswa. Tentu hal ini menarik untuk diteliti, sebab saat ini diperlukan suatu pembelajaran yang menarik agar mahasiswa nyaman saat pembelajaran berlangsung.

RECCE dapat digunakan untuk mengembangkan keterampilan pemecahan masalah mahasiswa serta mendorong mahasiswa untuk memahami matematika menggunakan contoh, tugas, maupun aktivitas yang berdasarkan kehidupan nyata (Chong et al., 2019). Dengan begitu maka RECCE dapat dapat diterapkan untuk mendukung kompetensi kognitif mahasiswa dan membuat mahasiswa lebih aktif saat pembelajaran.
Penggunaan kerangka kerja RECCE sangat sesuai apabila diterapkan atau digunakan pada mata kuliah yang dapat mengintegrasikan permasalahan ke dalam kehidupan nyata. Mata kuliah yang sesuai untuk penerapan kerangka kerja RECCE adalah mata kuliah geometri transformasi pada materi translasi.

Berdasarkan fakta di lapangan, diperlukan suatu kerangka kerja yang sesuai dengan materi yang akan dibahas, karena selama ini pada pembelajaran matematika jarang diterapkan pembelajaran yang menggunakan kerangka kerja. Padahal penggunaan kerangka kerja dapat membantu guru maupun dosen agar lebih bisa mengelompokkan kemampuan siswa maupun mahasiswa sesuai dengan komponen-komponen pada kerangka kerja yang digunakan. Dengan begitu maka mempermudah guru maupun dosen melakukan evaluasi.

Tujuan penelitian ini untuk mendeskripsikan penerapan pembelajaran matematika dengan menggunakan kerangka kerja RECCE untuk mendukung kompetensi kognitif mahasiswa.

\section{METODE PENELITIAN}

Penelitian yang dilakukan merupakan penelitian kualitatif deskriptif. Penelitian kulitatif deskriptif memiliki tujuan membuat gambaran secara akurat mengenai fakta maupun sifat-sifat yang berhubungan dengan penelitian (Sugilar, 2017). Penggunaan penelitian kualitatif deskriptif adalah untuk mengetahui dan menggambarkan bagaimana penerapan pembelajaran menggunakan kerangka kerja RECCE pada mata kuliah geometri transformasi terhadap kompetensi kognitif mahasiswa. Subjek penelitian ini adalah 33 mahasiswa, pendidikan matematika, 
Universitas Muhammadiyah Malang. Instrumen penelitian menggunakan lembar validasi dan lembar observasi keterlaksanaan pembelajaran. Lembar validasi digunakan untuk menilai keefektifan dan kesesuaian RPP yang berdasarkan kerangka kerja RECCE, dimana proses validasi ini dilakukan oleh dosen ahli, sedangkan lembar observasi keterlaksanaan pembelajaran berupa kegiatan-kegiatan pembelajaran yang dilaksanakan dengan mengobservasi kegiatan yang dilakukan oleh dosen serta respon mahasiswa terhadap kegiatan pembelajaran. Teknik pengumpulan data yang digunakan pada saat penelitian adalah observasi. Teknik analisis data kualitatif, terdiri dari reduksi data, penyajian data, serta penarikan kesimpulan dan verifikasi data.

Tahap yang pertama adalah mereduksi data. Tahap ini diawali dengan penerapan kerangka kerja RECCE pada materi translasi yang diikuti 33 mahasiswa. Tahap kedua adalah menyajikan data. Hasil pengamatan pada tahap reduksi dituangkan ke tahap ini. Pada tahap ini dijelaskan keaktifan mahasiswa selama pembelajaran sesuai dengan unsurunsur yang terkandung dalam RECCE yaitu realistic, educational, cognitive, contextual, and evaluation. Pada tahap ini hasil pengamatan disajikan dalam bentuk deskripsi. Tahap yang ketiga adalah penarikan kesimpulan sesuai dengan data dan hasil analisis yang telah dilakukan. Tahap yang terakhir adalah verifikasi data, dimana pada tahap ini dilakukan tinjauan ulang terhadap penelitian sebelumnya yang relevan dengan penerapan pembelajaran matematika menggunakan kerangka kerja, sebagai pembanding hasil analisis data dengan penelitian ini.

\section{HASIL DAN PEMBAHASAN}

Berdasarkan pengamatan yang telah dilakukan terhadap keterlaksanaan pembelajaran pada materi translasi, RECCE sudah berperan saat pembelajaran berlangsung. Hal tersebut dikarenakan mahasiswa lebih aktif dalam berdiskusi maupun bependapat mengenai adanya translasi dalam kehidupan sehari-hari. Berikut ini adalah hasil pengamatan keterlaksanaan pembelajaran yang didukung oleh kerangka kerja RECCE (Tabel 1).

Berdasarkan hasil pengamatan pada Tabel 1, kegiatan pertama yaitu memahami definisi translasi, unsur contextual pada RECCE menjadi pendukung kognitif mahasiswa. Meskipun unsur ini masih kurang terlihat dan kurang berperan dalam pembelajaran, tetapi mahasiswa sudah aktif berdiskusi bersama kelompok untuk memahami definisi translasi. Kegiatan yang pertama merupakan dasar dalam pembelajaran translasi agar mahasiswa lebih memahami materi sebagai bekal saat menyelesaikan masalah pada translasi. Pernyataan tersebut sejalan dengan pernyataan Varma \& Schwartz (2011) yang mengatakan bahwa perlunya persiapan yang baik dalam memahami konsep matematika agar dapat mengembangkan cara berpikir mahasiswa.

Kegiatan selanjutnya adalah menjelaskan definisi translasi. Berdasarkan hasil pengamatan terhadap keterlaksanaan pembelajaran pada tabel 1, mahasiswa dari perwakilan kelompok mampu menjelaskan definisi translasi sesuai dengan bahasa sendiri. Ada juga mahasiswa yang menjelaskan definisi dengan disertai contoh terjadinya translasi. Menurut mereka, penjelasan translasi yang disertai dengan contoh dapat membantu mahasiswa yang lain agar semakin mudah dalam memahami 
DOI: https://doi.org/10.24127/ajpm.v9i2.2599

seperi apa terjadinya translasi. Pada kegiatan kedua mahasiswa lebih aktif dalam pembelajaran. Keaktifan tersebut dapat dilihat dari hasil diskusi yang mana mahasiswa mampu menjelaskan definisi translasi secara deskriptif menggunakan bahasa sendiri dan mampu memberikan contoh kejadian translasi yang merupakan inisiatif sendiri tanpa perintah dosen. Keaktifan mahasiswa pada kegiatan kedua ini didukung oleh unsur educational pada kerangka kerja RECCE, dimana pada unsur ini keaktifan mahasiswa ditinjau dari aktivitas melalui pemberian contoh. Pada kegiatan kedua, penggunaan kerangka kerja RECCE pada pembelajaran translasi sudah mulai mendukung kompetensi kognitif mahasiswa melalui keaktifan mahasiswa dalam berdiskusi serta memberikan contoh.

Tabel 1. Hasil pengamatan keterlaksanaan pembelajaran menggunakan kerangka kerja RECCE.

\begin{tabular}{|c|c|c|}
\hline Kegiatan Pembelajaran & $\begin{array}{c}\text { Unsur } \\
R E C C E\end{array}$ & Kompetensi Kognitif \\
\hline 1. Memahami definisi translasi & Contextual & $\begin{array}{l}\text { Mahasiswa berdiskusi bersama kelompok } \\
\text { untuk memahami definisi translasi, dan } \\
\text { mengungkapkan definisi }\end{array}$ \\
\hline 2. Menjelaskan definisi translasi & Educational & $\begin{array}{l}\text { Mahasiswa dari perwakilan kelompok } \\
\text { dapat menjelaskan definisi translasi di } \\
\text { depan mahasiswa lain }\end{array}$ \\
\hline $\begin{array}{l}\text { 3. Memberikan contoh translasi } \\
\text { pada kehidupan nyata }\end{array}$ & $\begin{array}{l}\text { Educational } \\
\text { dan realistic }\end{array}$ & $\begin{array}{l}\text { Mahasiswa dapat memberi contoh } \\
\text { terjadinya translasi pada kehidupan nyata }\end{array}$ \\
\hline 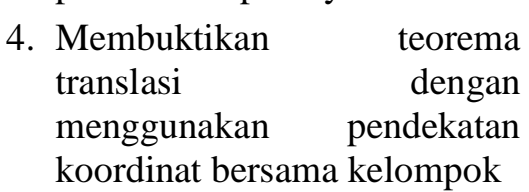 & Cognitive & $\begin{array}{l}\text { Mahasiswa dapat membuktikan teorema } \\
\text { translasi menggunakan pendekatan } \\
\text { koordinat dengan berdiskusi bersama } \\
\text { kelompok }\end{array}$ \\
\hline $\begin{array}{l}\text { 5. Menyelesaikan soal-soal } \\
\text { translasi dengan pendekatan } \\
\text { matriks bersama kelompok }\end{array}$ & Cognitive & $\begin{array}{l}\text { Mahasiswa dapat menyelesaikan soal yang } \\
\text { diberikan dengan berdiskusi bersama } \\
\text { kelompok }\end{array}$ \\
\hline $\begin{array}{l}\text { 6. Mempresentasikan hasil } \\
\text { diskusi mengenai translasi } \\
\text { dengan pendekatan matriks }\end{array}$ & Educational & $\begin{array}{l}\text { Mahasiswa dapat menjelaskan hasil } \\
\text { perkerjaan kelompok di depan kelas dan } \\
\text { dapat menjawab pertanyaan dari } \\
\text { mahasiswa kelompok lain }\end{array}$ \\
\hline $\begin{array}{l}\text { 7. Mahasiswa mengerjakan } \\
\text { LKM }\end{array}$ & Evaluation & $\begin{array}{l}\text { Mahasiswa mengerjakan LKM sesuai } \\
\text { pemahaman masing-masing. }\end{array}$ \\
\hline
\end{tabular}

Kegiatan kedua ini merupakan langkah awal dalam mendukung kompetensi kognitif mahasiswa setelah mahasiswa mampu memahami definisi translasi. Mahasiswa mulai berani mengungkapkan pendapat di depan teman sekelasnya dengan rasa percaya diri. Hal tersebut tentu menjadi awal yang baik dalam penelitian ini, sebab berdasarkan fakta di lapangan mahasiswa cenderung pasif dalam pembelajaran yang berhubungan dengan matematika. Mereka diselimuti rasa takut dan tidak percaya diri saat mengungkapkan pendapat. Itu sebabnya diperlukan suatu kerangka kerja yang dapat mendukung kognitif mahasiswa selama pembelajaran berlangsung. 
DOI: https://doi.org/10.24127/ajpm.v9i2.2599

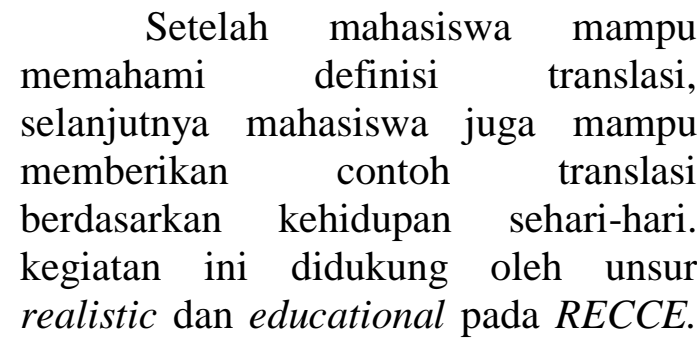
Penggunaan unsur realistic pada kegiatan ketiga karena kegiatan ini berhubungan dengan dunia nyata atau kehidupan sehari-hari. Pada kegiatan ketiga, terlihat jelas bahwa unsur realistic dapat mendukung kompetensi kognitif mahasiswa. Sedangkan unsur educational mendukung mahasiswa dalam memberikan contoh translasi terutama pada kehidupan sehari-hari.

Berdasarkan pada tabel 1 diperoleh bahwa Beberapa mahasiswa perwakilan kelompok mampu memberikan contoh terjadinya translasi pada kehidupan sehari-hari diantaranya adalah terjadinya translasi pada ubin lantai, terjadinya translasi pada bidak ratu, terjadinya translasi pada sebuah tangga yang dipindahkan dari tempat $A$ ke tempat $B$, terjadinya translasi pada seorang prajurit yang bersembunyi dan kemudian bergeser ke titik tertentu agar terhindar dari serangan lawan, dan terjadinya translasi pada saat bermain petak umpet. Pemberian contoh yang dilakukan mahasiswa-mahasiswa tersebut didukung oleh unsur educational. Kompetensi kognitif mahasiswa pada kegiatan ketiga mulai berkembang, sehingga peran kerangka kerja RECCE mulai terlihat dan mampu mendukung kompetensi kognitif mahasiswa.

Pemberian contoh translasi berdasarkan kehidupan sehari-hari membuat mahasiswa semakin memahami materi ini. Pendapat tersebut diperkuat oleh penelitian-penelitian sebelumnya yang juga mengatakan bahwa perlunya penerapan pembelajaran realistic pada matematika untuk mendukung pemahaman konsep mahasiswa sehingga kognitifnya dapat berkembang pesat (Karaca \& Ozkaya, 2017; Widada, Herawaty, \& Lubis, 2018)

Berdasarkan tabel 1, kegiatan keempat adalah membuktikan teorema translasi dengan menggunakan pendekatan koordinat. Mahasiswa mampu membuktikan teorema translasi menggunakan pendekatan koordinat dengan berdiskusi bersama kelompok. Mahasiswa terlihat bertukar pendapat dalam membuktikan, ada pula mahasiswa yang terlihat kebingungan pada saat berdiskusi berlangsung. Kegiatan keempat bertujuan untuk mematangkan konsep translasi mahasiswa dan memperkuat pemahaman mahasiswa mengenai konsep translasi. Mahasiswa yang paham mengenai pembuktian ini, membantu mahasiswa lain dalam satu kelompok yang masih bingung sampai mahasiswa tersebut paham. Inilah tujuan dari pembentukan kelompok pada pembelajaran translasi. Kegiatan keempat didukung oleh unsur cognitive pada kerangka kerja RECCE untuk mengembangkan keterampilan berpikir mahasiswa melalui komunikasi, pemecahan masalah dan pemberian solusi. Mahasiswa sudah mampu berkomunikasi dengan baik dalam satu kelompok, komunikasi tersebut juga berhubungan dengan pemberian solusi dalam membuktikan teorema translasi dengan pendekatan koordinat agar teorema tersebut terbukti.

$\begin{array}{llr}\text { Pada } & \text { Tabel } 1 \text { yang menjelaskan } \\ \text { hasil } & \text { pengamatan } & \text { terhadap }\end{array}$ keterlaksanaan pembelajaran, kegiatan kelima adalah menyelesaikan soal-soal translasi dengan pendekatan matriks bersama kelompok. Mahasiswa berdiskusi untuk menyelesaikan soal- 
soal yang disajikan. Sama halnya dengan kegiatan keempat, kegiatan ini juga bertujuan untuk memperkuat pemahaman mahasiswa mengenai translasi dengan pendekatan matriks. Mahasiswa dalam satu kelompok saling bekerja sama untuk menyelesaikan persoalan yang tersaji. Mahasiswa membagi tugas agar setiap anggota bekerja dan tidak memakan waktu terlalu banyak dan saling membantu ketika ada yang mengalami kesulitan. Pada kegiatan ini komunikasi yang terjalin antar mahasiswa dalam satu kelompok sudah terjalin sangat baik. Komunikasi yang baik juga berdampak pada keberhasilan kelompok dalam menyelesaikan soal-soal yang tersaji. Kegiatan kelima didukung oleh unsur cognitive.

Berdasarkan pada tabel 1, kegiatan keenam adalah mempresentasikan hasil diskusi mengenai translasi dengan pendekatan matriks. Karena kegiatan mempresentasikan maka mahasiswa dari setiap kelompok harus mampu menjelaskan hasil pekerjaan kelompok kepada mahasiswa yang lain. Mahasiswa yang menjelaskan adalah mahasiswa yang ditunjuk oleh dosen, maka dari itu semua anggota kelompok harus paham dan siap saat diminta untuk menjelaskan. Kegiatan keenam didukung oleh unsur educational karena berhubungan dengan aktivitas mahasiswa. Perwakilan mahasiswa setiap kelompok mampu menjelaskan hasil pekerjaan yang merupakan kegiatan berdiskusi. Hal tersebut karena adanya kegiatan berdiskusi sehingga mahasiswa yang kurang paham tidak sungkan untuk bertanya kepada mahasiswa yang paham dalam satu kelompok.

Berdasarkan hasil pengamatan keterlaksanaan pembelajaran pada Tabel
1, kegiatan ketujuh yang merupakan kegiatan akhir pada kegiatan inti adalah mengerjakan LKM secara individu. Pengerjaan LKM secara individu bertujuan untuk melihat pemahaman mahasiswa mengenai materi yang telah dipelajari. Pengerjaan LKM secara individu dilakukan sebagai bahan evaluasi dosen pada pembelajaran yang berlangsung. Kegiatan ini tentu sangat berpengaruh pada kompetensi kognitif. Kompetensi kognitif sudah terdukung dengan baik oleh RECCE apabila mahasiswa mampu memperoleh hasil yang baik pula. Kegiatan terakhir ini didukung oleh unsur evaluation.

Pembelajaran translasi yang didukung oleh kerangka kerja RECCE mampu mendukung keaktifan mahasiswa serta mendukung interaksi sosial antar mahasiswa melalui diskusi kelompok. Selain itu penyajian permasalahan nyata mampu mendukung kompetensi kognitif yang mengharuskan mahasiswa untuk berpikir kritis dalam menyelesaikan masalah nyata pada pengerjaan LKM. Hal tersebut didukung oleh penelitian terdahulu yang mengatakan bahwa penyajian permasalahan nyata yang mengharuskan mahasiswa menyelesaikan secara individu merupakan salah satu dukungan pada kognitif mahasiswa untuk memahami masalah tanpa melibatkan orang lain (Chong \& Shahrill, 2016).

Secara keseluruhan, kerangka kerja RECCE telah berpengaruh pada pembelajaran translasi. Penerapan kerangka kerja ini membuat mahasiswa aktif dalam pembelajaran melalui penugasan, pemberian contoh, menjelaskan, berdiskusi, dan memahami definisi. Mahasiswa lebih aktif pada saat pembelajaran karena ada motivasi dari dosen serta diri sendiri dan dukungan kerangka kerja yang 
DOI: https://doi.org/10.24127/ajpm.v9i2.2599

mampu mendukung kompetensi

kognitif mahasiswa. Berdasarkan

penelitian ini dapat dilihat bahwa

mahasiswa lebih memahami

pembelajaran yang bersangkutan

dengan kehidupan nyata (realistic).

Pernyataan tersebut sejalan dengan

pernyataan Lowrie \& Patahuddin (2015)

yang mengatakan bahwa penggunaan

kerangka kerja pada pembelajaran harus mempertimbangkan keaktifan mahasiswa serta mempertimbangkan kegiatan pembelajaran yang dikembangkan berdasarkan unsur atau prinsip kerangka kerja yang akan digunakan.

Adapun penelitian-penelitian yang sudah dilakukan menunjukkan hasil bahwa pembelajaran matematika realistic lebih baik jika diterapkan menggunakan kerangka kerja karena dapat melihat dan mengamati pemahaman siswa terhadap masalah nyata yang diberikan (Efriani, Putri, \& Hapizah, 2019). Penelitian lain mengenai penerapan kerangka kerja juga diungkapkan oleh Gusnindar, Sutrisno, \& Syaiful (2018) dimana hasil penelitiannya dalam menerapkan kerangka kerja mendapatkan respon yang positif dari siswa yang berdampak pada peningkatan ketrampilan berpikir siswa. Selain itu menurut Wardhani, Subanji, \& Dwiyana (2016) pada penelitiannya mengungkapkan bahwa penerapan pembelajaran matematika menggunakan kerangka kerja mendapatkan hasil yang baik karena dalam kerangka kerja terdiri dari beberapa unsur sehingga dapat terlihat keaktifan siswa berada pada unsur yang bagaimana.

Penerapan kerangka kerja RECCE pada materi translasi sudah terlaksana dengan baik. Kerangka kerja ini mampu mendukung kompetensi kognitif mahasiswa, dimana mahasiswa terlihat percaya diri saat memberi contoh nyata terjadinya translasi, aktif berdiskusi dan mengungkapkan pendapat, dan mampu menyelesaikan permasalahan dalam LKM yang berkaitan dengan terjadinya translasi pada kehidupan nyata. Hasil analisis pada penelitian ini semakin diperkuat oleh hasil penelitian Chong, Shahrill, \& Li (2019) yang mengatakan bahwa kerangka kerja RECCE sangat baik jika digunakan atau diterapkan pada materi yang dapat mengintegrasikan masalah nyata. Kartika, Sanapiah, \& Juliangkary (2017) juga mengatakan bahwa keberhasilan suatu pembelajaran karena faktor penerapan kerangka kerja yang baik dan sesuai dengan materi.

\section{KESIMPULAN DAN SARAN}

Dilihat dari pembelajaran yang berlangsung selama penelitian, kerangka kerja RECCE berhasil mendukung kompetensi kognitif mahasiswa. Mahasiswa berani dalam mengungkapkan pendapat, memberikan contoh nyata pada translasi, aktif dalam berdiskusi, menjelaskan definisi, membuktikan teorema, menyelesaikan masalah translasi yang disajikan, dan mampu mengerjakan LKM sesuai dengan pemahaman yang telah didapatsecara individu. Dengan begitu dapat dikatakan bahwa penggunaan kerangka kerja RECCE pada pembelajaran translasi sudah tepat dalam mendukung kompetensi mahasiswa.

Saran bagi peneliti selanjutnya boleh mengembangkan penelitian ini hingga ke tahap berikutnya seperti pemberian tes. Hal tersebut dilakukan agar mengetahui apakah kerangka kerja RECCE dapat meningkatkan kompetensi kognitif siswa atau mahasiswa atau hanya sebagai pendukung kompetensi kognitif saja. 
DOI: https://doi.org/10.24127/ajpm.v9i2.2599

\section{DAFTAR PUSTAKA}

Agrawal, J., \& Morin, L. L. (2016).

Evidence-Based Practices:

Applications of Concrete

Representational Abstract

Framework across Math Concepts

for Students with Mathematics

Disabilities. Learning Disabilities

Research and Practice, 31(1), 34-

44.

https://doi.org/10.1111/ldrp.12093

Akbay, L., Terzi, R., Kaplan, M., \&

Karaaslan, K. G. (2018). Expert

Based Attribute Identification and Validation on Fraction Subtraction:

A Cognitively Diagnostic Assessmen Aplication. Journal on Mathematics Education, 9(1), 103120.

Annur, M. F., Sujadi, I., \& Subanti, S. (2016). Aktivitas Metakognisi Siswa Kelas X SMAN 1 Tembilahan dalam Pemecahan Masalah Matematika Ditinjau dari Gaya Kognitif. Jurnal Elektronik Pembelajaran Matematika, 4(7), 720-730.

Ardiyani, S. M., Gunarhadi, \& Riyadi. (2018). Realistic Mathematics Education in Cooperative Learning Viewed From Learning Activity. Journal on Mathematics Education, 9(2), 301-310. Retrieved from https://files.eric.ed.gov/fulltext/EJ1 194281.pdf

Ariawan, R., \& Nufus, H. (2017). Hubungan Kemampuan Pemecahan Masalah Matematis dengan Kemampuan Komunikasi Matematis Siswa. Theorems (The Original Research of Mathematics), 1(2), 82-91. Retrieved from http://www.unma.ac.id/jurnal/inde x.php/th/article/view/384

Chong, M. S. F., \& Shahrill, M. (2016).
The Use of an Emerging Framework to Explore Students , Cognitive Competency. Indian Journal of Science and Technology, 9(16), 1-12. https://doi.org/10.17485/ijst/2016/v 9i16/78812

Chong, M. S. F., Shahrill, M., \& Li, H. C. (2019). The Integration of a Problem Solving Framework for Brunei High School Mathematics Curriculum in Increasing Student's Affective Competency. Journal on Mathematics Education, 10(2), 215-228.

Efriani, A., Putri, R. I. I., \& Hapizah. (2019). Sailing Context in PISALike Mathematics Problems. Journal on Mathematics Education, $\quad 10(2), \quad 265-276$. https://doi.org/10.22342/jme.10.2.5 245.265-276

Ekawati, R., Kohar, A. W., Imah, E. M., Amin, S. M., \& Fiangga, S. (2019). Students' Cognitive Processes in Solving Problem Related to The Concept of Area Conservation. Journal on Mathematics Education, 10(1), 21-36. https://doi.org/10.22342/jme.10.1.6 339.21-36

Gusnindar, Sutrisno, \& Syaiful. (2018). Pengembangan Perangkat Pembelajaran Matematika Berdasarkan Kerangka Kerja TPACK pada Materi Lingkaran untuk Mengoptimalkan Kemampuan Penalaran Deduktif. AKSIOMA: Jurnal Program Studi Pendidikan Matematika, 7(3), 403. https://doi.org/10.24127/ajpm.v7i3. 1557

Indriani, K. W. A. (2017). Analisis Kualitas Perancangan RPP dengan Menggunakan Kerangka Kerja ELPSA pada Focused Group Discussion di Kabupaten Sumbawa 
DOI: https://doi.org/10.24127/ajpm.v9i2.2599

Barat. Jurnal Didaktik Matematika, 4185, 25-34.

Karaca, S. Y., \& Ozkaya, A. (2017).

The Effects of Realistic

Mathematics Education on

Students ' Math Self Reports in Fifth Grades Mathematisc Course.

International Journal of Curriculum and Instruction, 9(1), 81-103.

Kartika, Y., Sanapiah, \& Juliangkary, E. (2017). Pengembangan Modul Pembelajaran Matematika dengan Kerangka ELPSA untuk Meningkatkan Kwmampuan Berpikir Kritis Siswa pada Materi Logika Matematika. JMPM, 5(1), 67-74.

Lowrie, T., \& Patahuddin, S. M. (2015). ELPSA as a Lesson Design Framework. Journal on Mathematics Education, 6(2), 115.

https://doi.org/10.22342/jme.6.2.21 66.77-92

Nurjaman, A., Purwasih, R., \& Sari, I. P. (2018). Meningkatkan Kemampuan Mahasiswa dalam Membuat RPP Melalui Penerapan Model Pembelajaran Project Based Learning. Jurnal Mercumatika, 2(2), 33-42. https://doi.org/10.15797/concom.2 019..23.009

Ramirez, G., Shaw, S. T., \& Maloney, E. A. (2018). Math Anxiety: Past Research, Promising Interventions, and a New Interpretation Framework. Educational Psychologist, O(0), 1-20. https://doi.org/10.1080/00461520.2 018.1447384

Sugilar, H. (2017). Daya Matematis Mahasiswa Program Studi Pendidikan Matematika. JNPM (Jurnal Nasional Pendidikan Matematika), $\quad$ 1(1), 97. https://doi.org/10.33603/jnpm.v1i1 .252

Varma, S., \& Schwartz, D. L. (2011). The Mental Representation of Integers: An Abstract-to-Concrete Shift in The Understanding of Mathematical Concepts. Cognition, 121(3), 363-385. https://doi.org/10.1016/j.cognition. 2011.08.005

Wardhani, W. A., Subanji, \& Dwiyana. (2016). Proses Berpikir Siswa Berdasarkan Kerangka Kerja Mason. Jurnal Pendidikan: Teori, Penelitian, Dan Pengembangan, 1(3), 297-313.

Widada, W., Herawaty, D., \& Lubis, A. N. M. T. (2018). Realistic Mathematics Learning Based on The Ethnomathematics in Bengkulu to Improve Students , Cognitive Level. Journal of Physics: Conference Series, 1088, 1-8. https://doi.org/10.1088/17426596/1088/1/012028 